\title{
Inhaltsverzeichnis
}

Theodor Fontane:

Grete Minde. Nach einer altmärkischen Chronik (1880) 3

\section{KOMMENTAR I}

Anja Schiemann:

Die Kunst der Abweichung - Fontanes Psychogramm einer Täterin ersetzt historischen Brandstiftungsprozess

KOMMENTAR II

Walter Zimorski:

„Es war ihr mehr auferlegt worden, als sie tragen konnte“.

Fontanes Debüt-Novelle „Grete Minde - Nach einer altmärkischen Chronik“.

Ein dramatisches ,Sitten- und Charakterbild“ 123

Walter Zimorski:

Theodor Fontanes werkbegleitende Briefzeugnisse

ABBILDUNGEN 
